\title{
Crono-bibliografía de Don Pedro Henríquez Ureña
}

\section{Advertencia}

M

I propósito al iniciar este trabajo, era sólo el de reconstruir la bibliografía de Pedro Henríquez Ureña. El copioso material que encontré en su archivo tanto como sus peculiaridades me obligaron a cambiar de rumbo. Trato de proporcionar hoy la trayectoria esquemática de esa vida rica en diversos intereses y preocupaciones, trayectoria que no pudo dejar de reflejarse en los escritos. Por eso he comenzado desde las poesías infantiles $\mathrm{y}$ he citado hasta los trabajos efímeros $\mathrm{u}$ ocasionales que revelan la aparición de preferencias y gustos; por eso he recogido los diferentes pseudónimos, máscaras distintas para distintas circunstancias; por eso, finalmente, me he atenido en lo posible a las fechas en que los trabajos fueron escritos y no a su aparición en revistas, periódicos o libros, aunque nunca he dejado de registrar también esos datos. Sé, sin embargo, que mi tarea ni es perfecta ni es exhaustiva; sé que padece de omisiones y que algunas veces las referencias son incompletas. Pero en otra oportunidad, con más tiempo y más calma, pondré término cumplido a mi labor.

Buena parte del éxito de mi trabajo se debe, como he dicho, a que he podido manejar el archivo de don Pedro, cuya viuda lo puso a mi entera disposición. También me han sido muy útiles, especialmente en lo que respecta al período 19241946, la "Bibliografía" elaborada por Julio Caillet-Bois* y el

* V. núm. 644, pp. 79-102. 
fichero de Sonia Henríquez Ureña de Hlito, quien había incorporado la bibliografía de Rodríguez Demorizi. Agradezco a don Alfonso Reyes su amable colaboración en la identificación de publicaciones aparecidas sin firma y el haberme permitido trabajar en su archivo; agradezco igualmente a mis amigos Ernesto Mejía Sánchez y Andrés R. Vázquez los datos que aportaron a mi investigación.

\section{CRONO-BIBLIOGRAFIA}

1894

1. "Mimisintinca" [poesía].

1896

2. "Beyita" [poesía]."

3. "María Reina" [poesía]."

4. "La noche y el mar" [poesía]."

5. "Ana Osorio" [poesía]. ${ }^{1}$

6. "A Josefa A. Perdomo" [poesía], agosto."

7. "A Colón" [poesía], octubre."

\section{7}

8. "La mariposa" [traducción de la poesía homónima del escritor catalán Pau Bunyegas]. ${ }^{3}$

9. "La mariposa" [traducción de Lamartine].

10. "Melancolía" [poesía].

11. "Shakespeare" [poesía].

12. "Tristezas. A la memoria de mis muertos" [poesía]," septiembre.

13. "Entre niños. Sucedido" [poesía], ${ }^{2}$ octubre.

14. "Aquí abajo" [traducción de la poesía homónima de Sully-Prudhomme , $^{3} L y C, 1^{\text {o }}$ de febrero de 1898; firmada Pedro Nicolás F. Henríquez Ureña.

15. "A Cuba" [poesía], octubre.

\section{8}

16. "El diluvio. Tradición de la isla de Haiti" [poesía]," agosto. 


\section{9}

17. “i Incendiada!" [poesía], ${ }^{2}$ marzo; $L y C$, junio 20 ; firmada Pedro N. Fed. Henríquez Ureña.

18. "El autor del primer himno. En memoria del decano de la poesía patria Félix María Delmonte" [poesía],2 abril o mayo.

19. "El mundo de las almas" [trad. de Sully-Prudhomme]," 29 de julio.

20. "El ideal" [trad. de Sully-Prudhomme], ${ }^{3}$ agosto.

21. "Ulises Hereaux", agosto.

\section{0}

22. "Crónica" [Recuerdo de José Joaquín Pérez], Revista Ilustrada, Santo Domingo, 15 de julio. ${ }^{5}$

23. "Teatrales. Virginia. La locura de amor", Lucha, 31 de julio. ${ }^{6}$

24. "Teatrales. Tamayo y Luisa Martínez Casado. La bola de nieve. Adriana Lecouvreur", Lucha, 17 de agosto. ${ }^{6}$

25. "Teatrales. Lola. Don Juan Tenorio", Lucha, 21 de agosto. ${ }^{6}$

26. "María del Carmen. Impresiones" [Sobre el drama de de Feliú y Codina], El Ibis, Santo Domingo, $1^{\circ}$ de septiembre; firmado Pedro N. Henríquez Ureña.

27. "Fiez-Vous" [trad. del poema homónimo del poeta haitiano Oswald Durand], ${ }^{3} N P, 15$ de octubre; firmado Pedro N. Henríquez Ureña.

28. "De poesía. A propósito de una obra" [La sensibilidad en la poesía cubana de Nicolás Heredia], NP, $1^{\circ}$ de diciembre; firmado Pedro N. Henríquez Ureña.

29. "Juan Gabriel Borkman, drama de Henrik Ibsen", NP, 15 de diciembre; firmado Pedro N. Henríquez Ureña.

30. "Rima negra" [poesía].7

31. "Las trágicas" [poesía], diciembre.

1901

32. "Editorial", $N P, 1^{\circ}$ de enero; ${ }^{5}$ Lucha, en el mismo mes. 33. "La belleza. Paráfrasis de un soneto de Baudelaire"," 
NP, 15 de enero; Germinal, Santiago de Cuba, diciembre de 1905. Firmado Pedro N. Henríquez Ureña.

34. "Belkiss" [sobre la obra de Eugenio de Castro], RevLit, abril o mayo; CLit, 14 de julio de 1904.

35. "Crónica neoyorkina. En el Metropolitan Opera House", RevLit, 8 de julio. ${ }^{6}$

36. "En el viento" [poesía], Ideal.

37. "Mariposas negras. Reminiscencias de Las mariposas negras de Schumann" [poesía], 7 octubre. Cuna, 8 de marzo de 1903; Fig, 28 de junio de 1903.

38. "Flores de otoño" [poesía fechada en Nueva York en octubre $],{ }^{8}$ Ideal, 4 de noviembre; firmada Pedro N. Henríquez Ureña. $C y A m, 2$ de julio de 1905 ; Por esos mundos, Madrid, octubre de 1905; Diario de la Marina, La Habana, 17 de noviembre de 1905 (tarde).

39. "Otoñal" [poesía fechada en Nueva York en octubre], ${ }^{8}$ Ideal, 18 de noviembre; La Vanguardia, Puerto Plata (Rep. Dominicana), noviembre; firmada Pedro N. Henríquez Ureña.

40. "Ensueño" [poesía fechada en Nueva York en diciembre], ${ }^{8}$ Cuna, 29 de mayo de 1904; CyAm, 13 de agosto de 1905.

41. "El verdadero Ibsen" [trad. y extracto de un artículo de William Archer], RevLit, $1^{\circ}$ de mayo; Cuna, 4 de septiembre de 1904.

1902

42. "Tropical" [poesía fechada en Nueva York el 12 de agosto]..$^{9}$

43. "En la cumbre" [poesía fechada en Nueva York en agosto], ${ }^{7} L D, 25$ de septiembre; El Civismo, Puerto Plata, septiembre; Azul y Rojo, La Habana, 31 de marzo de 1903. Firmada Pedro N. Henríquez Ureña.

1903

44. "Virginia Elena Ortea", Cuna, 3 de mayo; firmado P. N. Henríquez Ureña.

45. "Hostos" [Escrito con motivo de la muerte de Hostos y 
fechado en Nueva York], $L D, 29$ de septiembre; reproducido en Eugenio M. Hostos: biografía y bibliografía, Tip. de Oiga ..., Santo Domingo, 1905.

46. "Frente a las «Palisades» del Hudson" [poesía fechada en Nueva York en octubre], ${ }^{8}$ CLit, 14 de junio de 1904.

47. "Intima" [poesía fechada en Nueva York en diciembre], ${ }^{7}$ Cuna, 11 de septiembre de 1904.

48. "Neoyorkinas. Notas artísticas", Oiga..., 26 de diciembre.

49. "Postales" [poesías breves dedicadas a distintas personas $] .9$

1904

50. "Postales" [poesías breves dedicadas a distintas personas]. ${ }^{9}$

51. "Mercedes Mota", Actualidades, Lima.

52. "Literatura norteamericana", abril; Cuna, 22 de mayo.

53. "Música moderna" [poesía], Cuna, 1 de mayo; CMus, 15 de enero de 1905.

54. "La música nueva. La escuela italiana", CLit, 23 de julio; Páginas de Arte, El Salvador, núm. 3, febrero de 1906; Quincena, 15 de abril de 1906; El Heraldo Industrial, Caracas, $1^{\circ}$ de junio de 1906; Gaceta Musical, México, $1^{\circ}$ de agosto de 1906 [v. núm. 96].

55. "Crónica habanera", CLit, 21 de agosto.10

56. "Crónica habanera", CLit, 5 de septiembre. ${ }^{10}$

57. "Letras cubanas. I, El romanticismo de Enrique Piñeyro (París, 1904) ; II, Los poemas de Valdivia: «Melancolía» (junio, 1904); «Los vendedores del templo» (julio, 1904)", CLit, 5 de septiembre. La parte dedicada a Piñeyro se reprodujo en Cuna, 25 de septiembre.

58. "Ante el mar. Paráfrasis de un trozo de la oda «To the sea» de la poetisa norteamericana Amelie Rives", ${ }^{7}$ Cuna, 8 de enero de 1905; El Album, Santiago de los Caballeros, febrero de 1905; CLit, 10 de mayo de 1905; Dictamen, 3-4 de febrero de 1906.

59. "Crónica habanera", CLit, 5 de octubre. ${ }^{10}$

60. "Crónica habanera", CLit, 28 de octubre. ${ }^{10}$ 
61. "Escorzos. I, Adelina Patti ; II, Marcella Sembrich; III, Lillian Nórdica" [poesías], CMus, 15 de noviembre; Cuna, 11 de diciembre. "Adelina Patti" se publicó equivocadamente en The Monterrey News (1908) con la firma Gastón F. Deligne; "Marcella Sembrich" en ProIl, febrero de 1906.

62. “Crónica habanera. Italia Vitaliani”, CLit, 20 de noviembre. ${ }^{10}$

63. "Sobre la Antología", Cuna, 20 de noviembre; $A n, 5$ de febrero de $\mathbf{1 9 3 5 .}$

64. "Crónica habanera. La Vitaliani en Hedda Gabler", CLit, 28 de noviembre. ${ }^{10}$

65. "Dulce María Borrero", CLit, 28 de noviembre.

66. "La música nueva. Ricardo Strauss y sus poemas tonales", CMus, 15 de diciembre [v. núm. 96].

67. "Reflorescencia" [Sobre el poeta dominicano Gastón F. Deligne], Cuna, 18 de diciembre.

68. "Rasgos de un humorista" [George Bernard Shaw], CLit, 20 de diciembre [v. núm. 96].

69. "Ariel. La obra de José Enrique Rodó" [fechado el 31 de diciembre], CLit, 12 de enero de 1905 [v. núm. 96].

1905

70. "Crónica habanera", CLit, 20 de enero. ${ }^{10}$

71. "Oscar Wilde" [fechado en La Habana en febrero; v. núm. 96].

72. "Crónica habanera", CLit, 5 de febrero. ${ }^{10}$

73. "Los dramas de [Arthur Wing] Pinero", Discusión, 12 de febrero [v. núm. 96].

74. "Dos artistas" [Francisco García de Cisneros y Eleonora de Cisneros], CLit, 20 de febrero.

75. "Crónicas humanas. El libro de Muñoz Bustamante", CLit, 5 de marzo. 5

76. "Crónica habanera", CLit, 12 de marzo.10

77. "Correspondencia habanera", La Campaña, Santo Domingo, 17 de marzo.

78. "La profanación de Parsifal", CMus, 15 de abril [v. núm. 96]. 
79. “José Joaquín Pérez", CLit, 20 de abril; Cuna, 10 de febrero de 1907 [v. núms. 96 y 182].

80. "Lux" [poesía], CLit, 28 de abril; Quijote, t. 4, núm. 7, febrero de 1911.

81. "La serpentina" [poesía], CMus, 1" de mayo; Quincena, $1^{\circ}$ de junio; El Español, Mérida (Yucatán), 17 de diciembre; Dictamen, 14 de enero de 1906; Cuna, 23 de febrero de 1908.

82. "Correspondencia habanera", Tel, 20 de mayo.

83. "Correspondencia habanera", Tel, 10 de junio.

84. "Juan Guerra Núñez", CMus, 15 de junio.

85. "Máximo Gómez" [poesía fechada el 18 de junio], Discusión, 25 de junio; CLit, 28 de junio.

86. “D'Annunzio, el poeta", CLit, 21 de julio [v. núm. 96].

87. "Correspondencia habanera. La muerte de Máximo Gómez", $L D, 9$ de agosto.

88. “Tendencias de la poesía cubana”, Discusión, 13 de agosto [v. núm. 96].

89. "Correspondencia habanera", $L D, 22$ de agosto.

90. "Dos controversias shakespirianas", ProIl, septiembre.

91. "Todo lo que pasa es bello" [poesía fechada el 24 de octubre ], LHab, 15 de diciembre; Dictamen, 30-31 de diciembre; $M I l, 1906$; Revista Contemporánea, Monterrey, 1909; Osiris, enero 15 de 1910.

92. "Martí, escritor", Discusión, 25 de octubre; $L D, 25$ de oc-tubre [i es lo mismo de RepAm, 18 de febrero de 1931; Sur, 1931; Archivos de José Martí, año 4, núm. 7, mayodiciembre de 1943?].

93. "Hacia la luz" [poesía], $L H a b, 15$ de noviembre.

94. "Vencido (Síntesis)", IbAm, 15 de noviembre; $L H a b$, 15 de enero de 1906.

95. "Educación científica", $I b A m, 1^{\circ}$ de diciembre.

96. Ensayos críticos, Imprentá Esteban Fernández, La Habana, 1905. Recoge los núms. 54, 66, 68 [con el título "Tres escritores ingleses: Wilde, Pinero y Shaw"], 69, 71 , [véase supra], 73 [véase supra], 78, 79, 86 y 88 [coil el título "El modernismo en la poesía cubana"]. Contrene, además, "Rubén Darío", "Sociología (Hostos y Lluria)". 


\section{6}

97. "La intelectualidad hispano-americana" [En colaboración con Arturo R. de Carricarte], RevCrit, enero, pp. 1-9.

98. "Cuba (Notas de psicología literaria)", RevCrit, enero, pp. 10-19; Cuna, junio de 1907; MM, 1907.

99. Sobre Barrero Argüelles, Candentes, RevCrit, enero, pp. 23-24. ${ }^{5}$

100. Sobre Enrique José Varona, Curso de Psicología, RevCrit, enero, pp. 25-27.5

101. Sobre F. Carrera y Jústiz, Introducción a la historia de las instituciones locales de Cuba, RevCrit, enero, pp. 27-29.5

102. "Mitre" [nota necrológica], RevCrit, enero, pp. 29-30.5

103. "Pimentel Coronel" [nota necrológica], RevCrit, enero, pp. 30-31.5

104. "Crónica. Oyendo la banda de artillería", Dictamen, 1314 de enero. 5

105. "Ríe, payaso" [cuento], Dictamen, 27-28 de enero."11

106. "Notas editoriales e información", RevCrit, febrero, pp. 65-75 [Sobre: Rubén M. Campos, Claudio Oronoz; Luis Rosado Vega, Alma y Sangre; Francisco Elguero, Algunos versos; Delio Moreno Cantón, El sargento primero; Solón Argüello, El grito de las islas; Rafael Angel Troyo, Poemas del alma; Ramón Mez y Suárez, Observaciones sobre educación]." Con el título "Notas sobre Claudio Oronoz" y con firma completa se volvió a publicar el primer trabajo en RevMod, junio de 1906.

107. "Impresiones de la semana", Dictamen, 3 de marzo.

108. "Impresiones de la semana", Dictamen, 10 de marzo.

109. "Impresiones de la semana", Dictamen, 17 de marzo.

110. "El nuevo indígena", Dictamen, 21 de marzo.

111. "Impresiones de la semana", Dictamen, 31 de marzo.

112. "Impresiones de la semana", Dictamen, 7-8 de abril.

113. "Benavente. Los malhechores del bien", Dictamen, 9-10 de abril; Discusión, 22 de abril.

114. "Noches de arte. La desequilibrada de Echegaray. El flechazo de los Quintero", Dictamen, 10-11 de abril. 
115. "Impresiones de la semana", Dictamen, 14-15 de abril.

116. "Impresiones de la semana", Dictamen, 21-22 de abril.

117. "Los teatros en México", Dictamen, 7-8 de mayo.

118. "Henrik Ibsen" [reseña de su obra y de la crítica acerca de ella], Imparcial, 30 de mayo. ${ }^{5}$

119. "Teatros. Los conciertos. La ópera", SavM, junio.12

120. "Los restos de Colón. Famoso error histórico. Datos que comprueban la autenticidad de los restos existentes en Santo Domingo", Imparcial, 9 de junio. ${ }^{5}$

121. "México: La vida intelectual y artística", Discusión, 24 de junio.

122. "La resurrección de Don Juan", Dictamen, julio.

123. "Vida intelectual y artística. La influencia de Nietzsche. Anton Bruckner. Richard Strauss. La melodía. El modernismo español", $S a v M$, julio. ${ }^{12}$

124. "Teatros. Conciertos. La ópera", SavM, julio. ${ }^{12}$

125. "Edith Warton", RevMod, agosto.

126. "Lo que dice un dilettante. A propósito de la ópera de Castro" [La leyenda de Rudel], Imparcial, 5 de noviembre; firmado "Un Dilettante". Con el título "La leyenda de Rudel" en núm. 182.

\section{7}

127. "Julio Ruelas, pintor y dibujante", $M M$, marzo.

128. “... Un Libro!" [Sobre Gastón F. Deligne; fechado el 15 de marzo en México], Cuna, junio.

129. "Un clásico del siglo XX" [José María Gabriel y Galán], RevMod, julio; RepAm, 15 de diciembre de 1933 [v. núm. 182].

130. “Jesús E. Valenzuela", RevMod; MM; Cuna.

131. "Velada en la Preparatoria. Triunfo de Alfonso Reyes. Habla Justo Sierra", El Diario, México, julio.

132. "Conferencias y tés" [Carta a Enrique Ap. Henríquez sobre el movimiento de la literatura contemporánea en México], Cuna, 25 de agosto.

133. "Julio Flórez en México" [Carta a Enrique Ap. Henríquez], Cuna, núm. 37, 15 de septiembre. 
134. "Los de la nueva hora. Carlos González Peña”, Crónica, 15 de noviembre.

135. "El pinar" [poesía], RevMod; Cuna, 20 de octubre.

136. "Libros", RevMod, diciembre [firmado L. G.] ; Cuna, julio de 1908 [firmado Luis Gamia].

137. "Las conferencias de los jóvenes", La Gaceta de Guadalajara, Guadalajara (México), 17 de noviembre; MIl, México, 1910; LyP, t. 12, núm. 5, mayo de 1934 [con el título "Conferencias" en núm. 182].

138. "Fernando A. de Meriño", Crónica.

139. "Marginalia. José Enrique Rodó, RevMod..

140. "Genus Platonis", $L D$ [Con el título "El espíritu platónico" en núm. 182].

141. "Hostos o La concepción sociológica de Hostos". Reproducido en el libro de Enrique Deschamps La República Dominicana (Barcelona, 1907) ; Puerto Rico Ilustrado, marzo de 1924 y febrero de 1939; Clio, abril de 1939; América y Hostos, La Habana, 1939, pp. 149-155 [v. núm. 182].

142. "Poesías de Unamuno", RevMod; Cuna, 2 de febrero de 1908.

143. "Imitación d’annunziana" [poesía, fechada en México en 1907], Osiris, 1909; reproducida en Cortesía de Alfonso Reyes, México, 1948.

144. "El feminismo (Diálogo)", Dictamen.

145. "Crónica de la manifestación en memoria del Duque Job", $L D$.

\section{8}

146. "Días alcióneos", RevMod, enero; Cuna, 21 de junio; Osiris, 27 de febrero y 15 de agosto de 1910 [v. núm. 182].

147. "Alocución" [pronunciada en la Escuela Nacional Preparatoria de México al conmemorar al educador Gabino Barreda el 22 de marzo de 1908], Cuna, 17 de mayo [Con el título "Barreda", en núm. 182].

148. "Marginalia. El exotismo", Cuna, 25 de octubre; RevMod, diciembre; Osiris, $1^{\circ}$ de septiembre de 1910 [Con el título "El exotismo" en núm. 182]. 
149. "Galaripsos (Poesías de Gastón F. Deligne)", RevMod, octubre, [con el título "Gastón F. Deligne" en núm. 182]. Revisado y corregido fue incorporado al libro de Deligne en 1946 [Biblioteca Dominicana, vol. 3, Ciudad Trujillo].

150. "Alfonso Reyes. - «Invitación pastoral»" [poesía a la manera de...], Tilín, 22 de noviembre.

151. "Rafael López.-《Flor de infamia»" [poesía a la manera de...], Tilín, 22 de noviembre."

152. "Luis G. Urbina. - «Ingenua»" [poesía a la manera de...], Tilín, 6 de diciembre. ${ }^{5}$

153. "La catedral sin torre" [fechado en México en 1908]; con el título "La catedral" en núm. 182; NacT, 30 de septiembre de 1942.

154. "Walter Pater. Estudios griegos", México, ed. de Revista Moderna [traduc. de P.H.U.].

155. "Nota de edición al Ariel de Rodó", Talleres Lozano, Monterrey (México).

1909

156. "Crónica artística. La moda griega", Cuna, enero [Con el título "La moda griega" en núm. 182].

157. "El nacimiento de Dionisos. Esbozo trágico a la manera antigua", RevMod, febrero; Nov, 16 de diciembre de 1915 [v. núm. 335].

158. "Marginalia", Cuna, 17 de enero.

159. "Francisco García Calderón, «Las corrientes filosóficas en la América Latina»", transcripción y notas de P.H.U.; RevMod, febrero.

160. "Crónica de Nueva York. El Metropolitan y el Manhattan. Brillantes temporadas. Puccini. Nuevos estrenos. Otras novedades. Retiro de Marcel Sembrich. Otras novedades", TyM, 15 de febrero. ${ }^{13}$

161. "Cuestiones métricas. El verso endecasílabo", RevMod, marzo [v. núms. 182, 355, 634].

162. "Las cien mejores poesías", Cuna, 7 de marzo.

163. "Desde Nueva York. La retirada de Emma Eames. Réprise de Salomé. Una ópera de Smetana. Los encantos de Mary Garden. Obras maestras. El arte de Ludwig 
Wullner. Las novedades dramáticas. La Salomé de Strauss. Paderewsky", TyM, 15 de marzo.13

164. "Carta a Menéndez y Pelayo" [fechada el 28 de abril], $B B M P$, vol. 27, 1951.

165. "Nietzsche y el pragmatismo (Nota al vuelo)", RevMod, mayo [v. núm. 182].

166. "Un libro sobre el feminismo" [fechado en mayo; sobre M. Romera Navarro, Ensayo de una filosofía feminista], RevMod.

167. "Desde México" [Carta a Federico García Godoy], Cuna, 6 de junio [con el título de "Literatura histórica", v. núm. 182].

168. "Conferencias sobre el positivismo" [fechado el 21 de julio de 1909], RevMod, [con el título "El positivismo de Comte" en núm. 182].

169. "El positivismo independiente" [fechado el 25 de agosto], RevMod [v. núm. 182].

170. "A un vencido" [poesía], Fig; Cuna, 3 de octubre.

171. "A un poeta muerto" [poesía a René López], An-re, 13 de septiembre; Blanco y Negro, Santo Domingo, 19 de diciembre; Fig.

172. "Los mejores libros" [Enumeración de cien autores cuya lectura considera indispensable], $A n-r e, 20$ de septiembre [firmado Lilius Giraldus].

173. "Ibsen" [poesía], An-re, 20 de septiembre.

174. "Rosario Pino en Arbeu" [Crónica teatral], Act, 15 de octubre. ${ }^{12}$

175. "Señora ama de Benavente" [Crónica teatral], Act, 16 de octubre..$^{2}$

176. "Rosario Pino en El genio alegre" [Crónica teatral], Act, 17 de octubre. ${ }^{12}$

177. "La muerte de Clyde Fitch", Act, 25 de octubre [con el título "Clyde Fitch" en núm. 182].

178. "Despedida de Rosario Pino"[Crónica teatral], Act, 15 de noviembre. ${ }^{12}$

179. "Por la inmigración" [Carta a su tío Federico Henríquez y Carvajal], Oiga..., 20 de noviembre.

180. "Sobre Deligne" [Carta a J. Humberto Decoudray, fe- 
chada en México el 25 de noviembre de 1909], Ateneo, marzo de 1910.

181. Antología del Centenario. Compilación dirigida por Justo Sierra; colaboraron Luis G. Urbina, Pedro Henríquez Ureña y Nicolás Rangel [Estudio documentado de la literatura mexicana en el primer siglo de independencia].

182. Horas de estudio, Ollendorf, París, s. f. Contiene: "Días alcióneos" [núm. 146], "Cuestiones filosóficas" [núms. $168,169,165,141]$, "Literatura española y americana" [núms. 129, "Rubén Darío" (ya en núm. 96), 161], "De mi patria" [núms. 153, "La vida intelectual de Santo Domingo", 167, 79, 149], "Varia" [núms. 140, 148, 156, $177,126,137$ у 147].

183. "La musa bohemia" [acerca del libro homónimo de Carlos González Peña], MIl, enero.

184. "La tragedia de las rosas" [sobre la obra homónima de José Escofet], El Correo Español, México, 28 de febrero.

185. "El maestro Hernán Pérez de Oliva" [fragmento de un estudio leído en la sesión que el Ateneo de la Juventud de México dedicó a Rafael Altamira], La Unión Española, La Habana, febrero; Ateneo, junio [v. núms. 210, 390 y 593].

186. "Altamira en México", Ateneo, febrero-marzo.

187. "Profesores de idealismo" [Sobre Francisco García Calderón], Ateneo, agosto; RevMod.

188. "La obra de José Enrique Rodó" [conferencia pronunciada en el Ateneo de la Juventud de México el 22 de agosto], Conferencias del Ateneo de la Juventud, Imprenta Lacaud, México, 1910; Ateneo; Nos, enero de 1913; El Mes Literario, Coro (Venezuela), 1913.

189 "Cultura antigua de Santo Domingo, La Española" [extractos de lo relativo a Santo Domingo en la obra de Beristáin y Souza, Biblioteca Hispanoamericana Septentrional, precedidos de una nota explicativa; fechado en agosto], Ateneo, núms. 10-12, 14 y 17; 21 de noviembre y septiembre de 1911. 


\section{1}

190. "Electra y Hécuba" [fragmentos de una conferencia], $M I l$, febrero.

191. "Carta a Menéndez y Pelayo" [fechada el 15 de febrero], $B B M P$, vol. 27, 1951.

192. "Desde México" [Carta a Gustavo J. Henríquez acerca de su libro Trinos], Ateneo, núm. 15, marzo.

193. "Oyendo a Varona", Fig, 30 de abril.

194. "Las ideas sociales de Spinoza", Cuna, 28 de mayo y 4 de junio; $L D, 11$ de diciembre de 1932; Trap, septiembre-octubre de 1933.

1912

195. "La decadencia de la literatura descriptiva", Argos, México, 5 de enero; Cuna, 14 de enero.

196. "Carta abierta a Federico García Godoy" [acerca de su obra Alma dominicana; lleva fecha 25 de marzo en México], Ateneo, abril; Cuna, mayo.

197. "La Inglaterra de Menéndez y Pelayo" [fechado en México el 26 de abril], Cuna, 22 y 28 de febrero de 1914.

198. "Sobre la literatura descriptiva" [Carta a Charles Lesca acerca de su artículo "La decadencia de la literatura descriptiva"; fechada en México el 30 de abril], Cuna, julio.

199. "Carta al Director de El Imparcial" [acerca del supuesto nombramiento de P. H. U. en sustitución de Urbina], Imparcial, 9 de mayo.

200. "Rafael Cabrera y sus Presagios" [Conferencia leída en el Ateneo de la Juventud de México y fechada en agosto de 1912], Biblos, México.

201. "La ópera y la protección oficial", La Tribuna, México, 14 de noviembre [firmado L. G.].

1913

202. Tablas cronológicas de la literatura española, Universidad Popular Mexicana, México; $2^{n}$ ed., D. C. Heath y 
Co. Publishers, Boston y New York, 1920 [modificadas y ampliadas].

203. "Libros nuevos. Clásicos y modernos de Azorín", Páginas Blancas, \& ?; firmado Jusepe Vargas.

204. "La poesía perfecta", NosM, enero [es parte del artículo sobre Deligne, v. núm. 149].

205. "Valores de nuestra América. José Enrique Rodó", NosM, enero, núm. 45; Vang, 26 de enero y 2 de febrero de 1936.

206. "Traducciones y paráfrasis en la literatura mexicana de la época de la Independencia (1800-1821)", Anales del Museo Nacional de Arqueología, Historia y Etnografía, México, julio-agosto, vol. 5.

207. "Las audacias de Don Hermógenes" [crítica de la $A n$ tología de los mejores poetas castellanos de Rafael Mesa y López], NosM, septiembre; CCon, septiembre.

208. "Por el mismo camino" [cuento], $R A z$, septiembre.

209. "Jane Austen. La escritora femenina por excelencia", $R A z$, núm. 3, septiembre; Fig, 30 de noviembre; Cuna, junio de 1919 (v. núm. 450].

210. "El Renacimiento en España" [fragmento de una conferencia sobre el maestro Hernán Pérez de Oliva], Est, octubre [v. núms. 185, 244, 390 y 593].

211. "La métrica de los poetas mexicanos en la época de la Independencia" [Discurso de recepción en la sesión del 2 de octubre], Boletín de la Sociedad Mexicana de Geografía y Estadística, México, 1914, t. 7.

212. "La enseñanza de la literatura" [trabajo leído en el Ateneo de México en octubre], Revista Mexicana de Educación, diciembre; NosM, 1913-1914.

213. "Romances de América", CCon, noviembre-diciembre; La Lectura, Madrid, enero-febrero de 1914.

214. "Don Juan Ruiz de Alarcón" [conferencia pronunciada la noche del 6 de diciembre en la 3a. sesión organizada por Francisco J. de Gamoneda en la Librería General], NosM, marzo de 1914; Revista de Filosofía, Letras $y$ Ciencias de La Habana, 1915; LyP, tomo 10, núm. 2, abril de 1932; Vang, 12-19 de abril de 1936 [v. núm. 
452]. Hay trad. francesa en Bibliothéque Americaine, Univ. de París, 1924.

1914

215. La Universidad. Tesis para optar al título de abogado en la Escuela Nacional de Jurisprudencia de la Universidad de México, $H e R, 1919$.

216. "El Molière del siglo XX" [Conferencia sobre G. Bernard Shaw pronunciada el 7 de enero en la Asociación Cristiana de Jóvenes como representante de la Universidad Popular Mexicana].

217. "Sobre Dulce María Borrero", La Ilustración Semanal, México, 27 de enero.

218. "Carta a Julio Jiménez Rueda" [acerca del plan de estudios de la Escuela Preparatoria; lleva fecha 30 de enero], Est.

219. “El poeta del día en México" [Enrique González Martínez], Fig, 12 de abril.

220. "En pro de la edición definitiva de Sor Juana", México, México, 15 de abril.

221. "En defensa de la lírica española" [a propósito del discurso de Varona sobre la Avellaneda], Fig, 17 de mayo [los dos últimos párrafos, con el título "Los poetas líricos", en núm. 390].

222. "La vida literaria en Nueva York. La interesante encuesta de Times", Fig, julio. ${ }^{13}$

223. "La cultura de las humanidades", $\operatorname{RevBC}$, julio-agosto, vol. 9, núm. 4, pp. 242-252.

224. "Los valores literarios" [sobre el libro homónimo de Azorín], Fig, 2 de agosto [como primera parte de "Azorín" en núm. 390].

225. "Hojas" [prosa], LHab, 16 de agosto; Nov. 1915; Fig, 1919; UnHisp, 1919.

226. "Sutileza" [sobre Gutiérrez Nájera], Fig, 20 de septiembre; RevRev, $1^{\circ}$ de agosto de 1915.

227. "José de la Riva Agüero", Fig, 18 de octubre.

228. "Ante la tumba de Casal", Fig, 25 de octubre.

229. "De viajes", $\mathrm{HeCu}, 25$ de noviembre. ${ }^{14}$ 
230. "Cuba en Nueva York", $\mathrm{HeCu}, 26$ de noviembre. ${ }^{14}$

231. "Desde Washington. Hacienda y diplomacia", $\mathrm{HeCu}, 28$ de noviembre. ${ }^{14}$

232. "Desde Washington. Sin brújula", HeCu, 29 de noviembre. ${ }^{14}$

233. "Desde Washington. En torno a la doctrina Taft", HeCu, diciembre. ${ }^{14}$

234. "Desde Washington. ¿Abstención al fin?", $\mathrm{HeCu}, 7$ de diciembre. ${ }^{14}$

235. "Desde Washington. La despedida de Anatole France", $\mathrm{HeCu}, 7$ de diciembre. Con el título "Anatole France's valedictory", en The Forum, New York, October, vol. 54, núm. 4, pp. 479-481.

236. "Desde Washington. La neutralidad panamericana" $\mathrm{HeCu}, 14$ de diciembre. ${ }^{14}$

237. "Desde Washington. Inquietudes", $\mathrm{HeCu}, 21$ de diciembre. ${ }^{14}$

238. "Desde Washington. Contienda de universitarios", He$C u, 23$ de diciembre. ${ }^{14}$

239. "Desde Washington. La resurrección de la danza", $\mathrm{HeCu}$, 25 de diciembre.

240. "Desde Washington. Inglaterra ayer y hoy", $\mathrm{HeCu,26}$ de diciembre. La segunda parte de este artículo fue reproducida en VidM, junio de 1916.

241. "Desde Washington. La templanza obligatoria", $\mathrm{HeCu}$, 28 de diciembre. ${ }^{14}$

242. "Desde Washington. El dominio de los empleos públicos", $\mathrm{HeCu}, 29$ de diciembre. ${ }^{14}$

243. "Desde Washington. Vanidad nacional", $\mathrm{HeCu}, 31$ de diciembre. ${ }^{14}$

244. "Estudios sobre el Renacimiento en España. El maestro Hernán Pérez de Oliva", CCon, año 2, t. 4, hay tirada aparte [v. núms. 185, 210, 390 y 593].

245. "Rioja y el sentimiento de las flores", Revista de América, París ; España, núm. 131, 1920 [v. núms. 390 y 593].

246. "Lacrimae rerum" [dedicado a Pablo Martínez del Río y Vinent], Nov, 1915; UnHisp, 1919; Cuna, enero de 1920 . 


\section{5}

247. "La poesía de Enrique González Martínez" [Prólogo a La muerte del cisne, fechado en Washington en 1915], CCon [v. núm. 452].

248. "Desde Washington. La primera rebeldía", $\mathrm{HeCu}, 2$ de enero. ${ }^{14}$

249. "Música nueva", $\mathrm{HeCu,3}$ de enero.

250. "Desde Washington. ¿Cuál es el remedio?", $\mathrm{HeCu}, 6$ de enero. ${ }^{14}$

251. "Desde Washington. Los empleos y la democracia", $H_{-}$ $C u, 9$ de enero. ${ }^{4}$

252. "Desde Washington. La necesidad del éxito", $\mathrm{HeCu}, 12$ de enero.

253. "Desde Washington. El derecho al milagro", $\mathrm{HeCu}, 13$ de enero. ${ }^{14}$

254. "Desde Washington. La ilusión de la paz", $\mathrm{HeCu}$; $^{14} \mathrm{El}$ Progreso, Santo Domingo, 7 de marzo. ${ }^{12}$

255. "Desde Washington. El sufragio femenino", $\mathrm{HeCu}, 20$ de enero. ${ }^{14}$

256. "Desde Washington. Máquinas de conferencias", $\mathrm{HeCu}$, 21 de enero. ${ }^{14}$

257. "Desde Washington. La protección del partido", $\mathrm{HeCu}$, 23 de enero. ${ }^{14}$

258. "Ciudades escépticas", $\mathrm{HeCu}, 23$ de enero. ${ }^{14}$

259. "Desde Washington. El castigo de la intolerancia", $\mathrm{He}$ $C u, 27$ de enero. ${ }^{14}$

260. "La inmigración", $\mathrm{HeCu}, 30$ de enero. ${ }^{14}$

261. "Desde Washington. Sajones y latinos", $\mathrm{HeCu}, 31 \mathrm{de}$ enero $;^{\mathbf{1 4}}$ se publicó arreglado en Nov y en Patria, México, octubre de 1916.

262. "Desde Washington. Pintores norteamericanos", $\mathrm{HeCu}$, 3 de febrero.

263. "El triunfo de lo efímero", $\mathrm{HeCu}, 6$ de febrero. ${ }^{14}$

264. "La muerte del sabio", $\mathrm{HeCu}, 8$ de febrero. ${ }^{14}$

265. "Desde Washington. El crepúsculo de Wilson", $\mathrm{HeCu}$, 11 de febrero. ${ }^{14}$

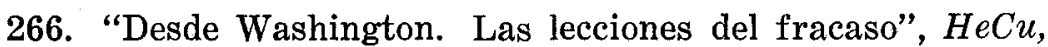
19 de febrero. ${ }^{14}$ 
267. "Homenaje a un pueblo en desgracia", HeCu, 22 de febrero $;^{14}$ El Progreso, Santo Domingo, 18 de abril..$^{12}$

268. "Desde Washington. La publicidad en los negocios", HeCu, 24 de febrero. ${ }^{14}$

269. "Desde Washington. La exposición de San Francisco", $\mathrm{HeCu}, 28$ de febrero. ${ }^{14}$

270. "Beethoven y.Wagner", $\mathrm{HeCu}, 3$ de marzo; modificado, en Nov, 22 de octubre.

271. "Desde Washington. Habla Wilson", $\mathrm{HeCu,6}$ de marzo. ${ }^{14}$

272. "Desde Washington. La eficacia de los congresos", $\mathrm{He}$ Cu, marzo. ${ }^{14}$

273. "Desde Washington. Acuarelas y retratos". $\mathrm{HeCu}, 18 \mathrm{de}$ marzo.

274. "España y los Estados Unidos", $\mathrm{HeCu}, 12$ de marzo; Cuna, $1^{\circ}$ de mayo, [sin el índice final de hispanistas]; Colec. Ariel, San José de Costa Rica.

275. "Pigmalión contra Galatea", $\mathrm{HeCu}, 31$ de marzo [v. núm. $450]$.

276. "El problema del secretario de Estado", $\mathrm{HeCu}, 9$ de abril. ${ }^{14}$

277. "Apertura de la Conferencia Panamericana", Nov, 27 de mayo. ${ }^{14}$

278. "Danzas y tragedias" [Isadora Duncan], Fig. mayo o junio.

279. "Instituciones, leyes y costumbres. La institución del Homestead", Nov, 8 de julio. ${ }^{5}$

280. "La enseñanza del castellano como necesidad nacional en los Estados Unidos", Nov, 8 de julio. ${ }^{5}$

281. "La muerte de Porfirio Díaz", Nov, 15 de julio. ${ }^{5}$

282. "Instituciones, leyes y costumbres. Problemas penales", Nov, 15 de julio. ${ }^{5}$

283. "Nieves Xenes", Nov, 22 de julio.

284. "Salomón de la Selva", Nov, 22 de julio. ${ }^{5}$

285. "Instituciones, leyes y costumbres. Delincuentes y locos", Nov, 22 de julio. 5

286. "Instituciones, leyes y costumbres. Las universidades como instituciones de derecho público. Conflictos universitarios. ¿Quién es el dueño de las universidades?", Nov, agosto. ${ }^{5}$ 
287. "Libros e ideas. ¿Pierde América una gloria literaria? [Se refiere a Henry James que acababa de dejar su ciudanía norteamericana]. Libro sobre Haití [T. Lothrop Toddard, The French Revolution in Santo Domingo]", Nov, agosto. ${ }^{5}$

288. "Bernard Shaw", Nov, 26 de agosto. 5

289. "Poetas de los Estados Unidos", Fig, septiembre.

290. "Richard Middleton", Nov, 2 de septiembre ;" RevInd, septiembre. ${ }^{12}$.

291. "Alice Meynell”, Nov, 9 de septiembre. ${ }^{5}$

292. "Libros e ideas. Literatura holandesa", Nov. 30 de septiembre. ${ }^{5}$.

293. "Instituciones, leyes y costumbres. La educación del abogado", Nov, 30 de septiembre. ${ }^{5}$

294. "Despertar" [poesía; Rodríguez Demorizi la considera de 1910], Nov, 30 de septiembre.

295. "La retirada de Julia Marlowe. Los teatros de repertorio", Nov, 7 de octubre. ${ }^{5}$

296. "Exposiciones. Bandbox Theatre", Nov, 14 de octubre."

297. "Exposiciones. Manhattan Opera House", Nov, 28 de octubre.5

298. "Stevenson", Nov, 4 de noviembre. ${ }^{5}$

299. "Manhattan Opera House", Nov, 11 de noviembre.

300. "Conciertos. Metropolitan Opera House. El drama", Nov, 18 de noviembre..$^{5}$

301. "En honor de Chocano", Nov, 18 de noviembre.

302. "El romance español en los Estados Unidos", Nov, $18 \mathrm{de}$ noviembre. 5

303. "Metropolitan Opera House", Nov, 25 de noviembre..$^{5}$

304. "El baile", Nov, 25 de noviembre."

305. "Conciertos. Metropolitan Opera House", Nov, 2 de diciembre. 5

306. "La filosofía de la América Española", Nov, 2 de diciembre. ${ }^{5}$

307. "Thomas Walsh", Nov, 2 de diciembre; convertido en artículo en Fig. 6 de febrero de 1916.

308. "Exposiciones. Conciertos. Metropolitan Opera House", Nov, 9 de diciembre..$^{5}$

309. "El mejor libro del año", Nov, 9 de diciembre. 
310. "Eurípides", Nov, 16 de diciembre. 5

311. "Exposiciones. Nuevo poema de Sibelius. Conciertos. La ópera. Los Tejedores", Nov, 16 de diciembre. ${ }^{5}$

312. "Exposiciones. Conciertos. Yvette Guilbert", Nov, 23 de diciembre. ${ }^{5}$

313. "Libros e ideas. La arquitectura mexicana", Nov, 30 de diciembre. 5

314. "La ópera", Nov, 30 de diciembre.

315. "Artes y teatros. Exposiciones. El estreno de El Príncipe Igor", Nov, 6 de enero. 5

316. "Artes y teatros. Exposiciones. La culminación de la temporada musical. La presentación de Granados", Nov, 27 de enero. 5

317. "El baile ruso", Nov, 27 de enero.

318. "Gaultier juzgado por Casseres", Nov, 27 de enero..$^{5}$

319. "Goyescas", Nov, 3 de febrero; modificado y ampliado, en España, 8 de enero de 1920 [v. núm. 390].

320. “Artes y teatros. María Barrientos. La ópera. El baile ruso. Conciertos. Drama. La Isla del Tesoro. Exposiciones", Nov, 3 de febrero. 5

321. "Artes y teatros. Exposiciones recientes. Conciertos. La ópera", Nov, 10 de febrero. ${ }^{12}$

322. "Cézanne", Nov, 17 de febrero. ${ }^{12}$

323. "Rubén Darío", Nov, 17 de febrero. Incorporado como prólogo a Eleven poems of Rubén Darío, Hispanic Society of America, 1916.

324. “Arte y teatros. El Don Quijote de Strauss. Pablo Casals. La ópera. Centenario de Shakespeare. Drama. Exposiciones recientes", Nov, 24 de febrero.

325. "Aelian Hall. Concierto del maestro Granados", Nov, 24 de febrero.

326. "Arte y teatros. Exposiciones. La ópera. Conciertos. Teatros. Centenario de Shakespeare", Nov, 2 de marzo.

327. "De la nueva interpretación de Cervantes" [del Quijote], Nov, abril; La Nación, La Habana, mayo; Colec. 
Ariel, núm. 79, San José de Costa Rica [con el título "Cervantes" y modificado en núm. 390].

328. "El primer libro de escritor americano", $R R$, vol. 7 , núm. 3, julio-septiembre, pp. 284, 287; Boletín de la Biblioteca Nacional de México; RevFil, 1918; Cuna, 1919; traducido al inglés en Inter America, New York, 1918, vol. 1, núm. 6, pp. 389-392.

329. "Danza de los rayos de sol" [traduc. de "Dance of the Sunbeams" de Bliss Carman, VidM, 16 de agosto.

330. "La República Dominicana", CCon, septiembre, t. 15, núm. 1, pp. 38-49.

331. "My country. 'tis of thee" " [Carta en inglés al editor de The Journal, Minneapolis, fechada el 28 de septiembre en Minnesota], 3 de octubre.

332. "El despojo de los pueblos débiles", RUniv, octubre; $E l$ Tiempo, Santo Domingo, 16 de noviembre. ${ }^{14}$

333. "José Echegaray" [en colaboración con Martín Luis Guzmán], RUniv, noviembre.

334. "Rubén Dario", The Minnesota Magazine, Minneapolis, [¿es el núm. 323?]

335. El nacimiento de Dionisos, Imp. de Las Novedades, New York [v. núm. 157].

336. Introducción al libro de Mariano Brull, La Casa del silencio.

\section{7}

337. "Artes y teatros. La ópera. La orquesta sinfónica. Sociedad filarmónica. Música de cámara. Guiomar Novaes. La serie histórica de Gabrilowitsch", Nov, 12 de marzo.

338. "Bibliografía de Sor Juana Inés de la Cruz", $R H i$, vol. 40, julio, núm. 97, pp. 161-214; LyP, febrero de 1934 (pp. 72-78), marzo de 1934 (pp. 137-143), abril de 1934 (pp. 175-179), mayo de 1934 (pp. 229-235), junio de 1934 (pp. 290-298), julio de 1934 (pp. 336-344), agosto de 1934 (pp. 386-393), septiembre de 1934 (pp. 436-441) [con notas de Hermilo Abreu Gómez] ; BICLA, 1937 y 1942 [corregida y aumentada]. 
339. "Literatura dominicana", $R H i$, agosto, núm. 98 , tomo 40 , pp. 273 y ss.; BIUP, abril de 1918.

340. "Un problema literario" [Carta de Enrique José Varona a P. H. U. y contestación de éste acerca de Sor Juana Inés de la Cruz], CCon, 15, pp. 38-49; La Primada de América, Santo Domingo, 15 de diciembre.

341. "Notas sobre Pedro Espinosa", $R F E$, julio-septiembre, t. 4, pp. 289-292.

342. "Campoamor", $R H i$, t. 41, pp. 683-688.

343. "El espíritu y las máquinas. Impresiones de un viaje a España", El Gráfico, New York, octubre; Baja California, San Diego, 1918; Panorama Mundial, México, 1918; UnHisp, 1919 [v. núm. 390].

344. "Opera Review", MinD, 27 de noviembre.

\section{8}

345. "El niño" [poesía], Fig, enero.

346. "Nuevas poesías atribuídas a Terrazas", $R F E$, eneromarzo, t. 5, pp. 49-56.

347. "Las «nuevas estrellas» de Heredia", $R R$, enero-marzo, pp. 112-114.

348. "A Mexican writer" [Alfonso Reyes], MinD, 1" de marzo.

349. "Antología de la versificación rítmica" [prólogo fechado en Minnesota en mayo], Colec. El Convivio, San José de Costa Rica; $2^{\text {a }}$ ed. Ed. Cultura, México, t. 10, núm. 2, 1919 [retocada y ampliada].

350. "On the dance", RevInd, septiembre.

351. C. Fontaine, En France. Edición francesa española de P. H. U., Nueva York.

352. "La obra de Juan Ramón Jiménez" [fechado en Minneapolis en 1918], CCon, 1919; RepAm, 1920; prólogo de Poesías de Juan Ramón Jiménez, Ed. Cultura, México, 1923 [v. núm. 390].

353. Sobre Carl Van Vechten, The Music of Spain. Hisp.

1919

354. "La lengua de Santo Domingo" [rectificación a MeyerLübke], Revistas y Libros, Madrid; RepAm, 1920. 
355. "El endecasílabo castellano", $R F E$, abril-junio, t. 6, pp. 132-157 [v. núms. 161, 182 y 634].

356. "La enseñanza de la sociología en América" [carta a Arturo de la Mota], Nos, junio.

357. "Espinosa y Espronceda", $R F E$, julio-septiembre, t. 6, p. 309.

358. "El apogeo de la versificación irregular (1600-1675)", Nos, diciembre, pp. 445-451 [fragm. del cap. 4 del núm. $359]$.

\section{0}

359. La versificación irregular en la poesía castellana, Public. de la $R F E$, Madrid; $2^{\text {a }}$ ed., 1933 [corregida y adicionada]; $3^{a}$ ed., Buenos Aires [incluida en una edición que prepara la Facultad de Filosofía y Letras; contendrá todos los trabajos sobre versificación].

360. "Lecturas. Teatro, siglos XIX y Xx", Junta para la Ampliación de Estudios, Madrid.

361. "La versificación irregular en la poesía castellana" [introd. al número 359], CCon.

362. José Moreno Villa, Florilegio (prosa y verso), Sel. y pról. de P. H. U., San José de Costa Rica. Incluído en núm. 390 ; reprod. en RepAm.

363. "El idioma castellano es tal popular en los bulevares de París como en Nueva York...", Pr, 8 de enero.

364. "Estudios sobre Rodó" (I. A [lfonso] R [eyes] ; II, P. H. U.), El Sol, Madrid, 22 de enero.

365. Sobre J. L. Ferguson, American Literature in Spain. $R F E$, enero-marzo, t. 7, pp. 62-71.

366. "La cultura y los peligros de la especialidad", UnHisp, 11 de febrero; Nos, septiembre de 1922, pp. 47-54.

367. "Desde Madrid. Los hispanoamericanos en España" [firmado el 8 de marzo], Pr. $^{14}$

368. Sobre Pérez y Curis, El Marqués de Santillana, $R F E$, abril-junio, pp. 188-189.

369. "El último libro de Luis G. Urbina Estampas de viaje", Sol del Domingo, \&?, 17 de julio.

370. "Bibliografía literaria de Santo Domingo", RepAm. 
371. "La renovación del teatro. La historia del escenario. El escenario como cuadro. El odiado siglo XIX. ¿Para qué sirve el realismo? La solución «artística». La solución histórica. La solución radical. Soluciones mixtas. El caso de Nueva York. La mejor solución", España, núm. 256. Modificado fue leído en Amigos del Arte (Buenos Aires) y publicado en Social, 1925; Val, t. 3, núm. 9, marzo de 1926, pp. 210-221 [Con el título "Hacia el nuevo teatro" en núm. 452].

372. "De la prosa castellana", España, núm. 267.

373. "Pérez Galdós", UnHisp.

374. Adolfo Salazar, Andrómeda; pról. de P. H. U. Ed. Cultura, México, t. 13, núm. 6 [v. núm. 390].

375. Lenín, El estado y la revolución proletaria. Trad. del inglés por P. H. U., Carlos Pereyra y Alfonso Reyes. Biblioteca Nueva, Madrid.

376. Oscar Wilde, El huerto de las granadas, El retrato de Mr. W. H. y Salomé. Trad. con la firma E. P. Garduño. Biblioteca Nueva, Madrid.

\section{1}

377. Sobre M. Do Carmo, Consolidaçao das leis do verso. $R F E$, enero-marzo, pp. 84-85.

ธ̌78. "En defensa de la Revista de Filología Española" [Carta a Joaquín García Monge], RepAm, 1 de marzo.

379. "Observaciones sobre el español en América", $R F E$, octubre-diciembre, pp. 357-390 [v. núms. 462 y 464].

380. "Rubén Darío y el siglo xv", RHi, t. 50.

381. Hilaire Belloc, Orígenes del sistema representativo de gobierno. Trad. de P. H. U., CCon.

\section{2}

382. "En la orilla" [distintos fragmentos], RepAm, 27 de febrero; Indice, Madrid; $M M$; El Sur, Azua (Santo Domingo), 19 de enero de 1923; RepAm, 19 de marzo de 1923; Nos, abril de 1923; Cuna, agosto de 1923; CCon, $124 ; M F, 5$ de agosto de 1925 [con el título "Preliminares" en núm. 390]. 
383. "Miniaturas mexicanas", Nos, abril, pp. 455-459.

384. "Puntos de conferencia dada en inglés ante el Club de Relaciones Internacionales de la Univ. de Minnesota" [Relaciones de Estados Unidos y el Caribe], HeR, 15 de mayo.

385. "Carta y programa a un tiempo" [a Joaquín García Monge a propósito de la orientación de Repertorio Americano], RepAm, 26 de junio.

386. "Notas sobre literatura mexicana", $M M$, año 2, núm. 3 [como apostilla a "Enrique González Martínez", en núm. $452]$.

387. "Discurso en homenaje a Vasconcelos", Nos, octubre, pp. 245-247.

388. "Arte mexicano", Mundo. ${ }^{10}$

389. Juan Ruiz de Alarcón, Los favores del mundo. Ed., pról. y notas de P. H. U.; Ed. Cultura, México, t. 16, núm. 4.

390. En la orilla. Mi España, Ed. de México Moderno, Méxi.co. Contiene: núms. 382, 343; "De París a Madrid"; "La Antología de la ciudad"; Letras-Artes: núms. 374, 319, 362, 352 ; “Azorín" [núm. 224 ; "Los clásicos españoles", "Azorín y Menéndez Pelayo", "El criterio académico", "La verdadera labor de Menéndez Pelayo", "Antiguos y modernos". "Azorín renovador", "Antologías de prosistas", "La prosa castellana"]; El Renacimiento en España: "Explicación", núms. 245, 221, 327, 207 [modificado], 244.

\section{3}

391. "Benavente", Mundo, febrero. ${ }^{5}$

392. "Libertad de los pueblos pequeños y el Senado norteamericano" [Carta al senador Lodge], HeR, 15 de febrero.

393. "La compañía del Teatro de la Porte St. Martin en el Arbeu. El Filibustero y Bourbouroche", Mundo, 21 de abril [firmado L. R.]

394. "El jueves se inaugurará, en el Iris, la temporada de ópera rusa con Boris Godunov", Mundo, 26 de junio.1.5

395. "La compañía de ópera rusa obtuvo un estupendo éxito 
en el teatro Esperanza Iris. El Boris Godunoff abre la temporada de arte ruso", Mundo, 29 de junio. ${ }^{15}$

396. "Un nuevo triunfo por la compañía de ópera rusa que actúa en el Iris. La representación de la ópera de Rimsky-Kórsakov $L a$ doncella de nieve forma interesante contraste con Boris Godunov", Mundo, 30 de junio..15

397. "El Demonio de Rubinstein revela otro aspecto de la ópera rusa", Mundo, julio. ${ }^{15}$

398. "Diego Rivera", Mundo, julio; Social.

399. "Estreno de Eugenio Onieguin", Mundo, 6 de julio. ${ }^{15}$

400. "Pique Dame del gran compositor ruso obtuvo éxito la noche de su estreno en el teatro Iris", Mundo, 12 de julio. ${ }^{15}$

401. "Tosca y La prometida del Czar por la compañía de ópera rusa", Mundo, 24 de julio. ${ }^{15}$

402. "Breves nociones de filología", Pan, terminó de publicarse el 30 de agosto.

403. "La doctrina peligrosa" [acerca del discurso de Hugues y la nueva interpretación de la doctrina Monroe], Mun$d o, 3$ de septiembre.

404. "El hermano definidor", Mundo, 5 de septiembre.

405. "El primer concierto de Arthur Rubinstein en el teatro Arbeu", Mundo, 13 de septiembre. ${ }^{15}$

406. "Nuevo triunfo de Rubinstein", Mundo, 15 de septiembre. ${ }^{15}$

407. "Arthur Rubinstein tocó el Carnaval ayer en el Arbeu", Mundo, 17 de septiembre. ${ }^{15}$

408. "Los conciertos de Arthur Rubinstein en Arbeu", Mundo, 24 de septiembre.15

409. "Rubinstein toca música nueva", Mundo, 27 de septiembre..$^{\bar{a}}$

410. "Las dos Américas. Lo que pueden darse mutuamente", $\operatorname{RepAm}, 1^{\circ}$ de octubre.

411. "Movimiento artístico. Rubinstein", Mundo, 4 de octubre. ${ }^{15}$

412. "El hermano definidor. La doctrina peligrosa". Diario de Cuba, Santiago de Cuba, 7 de octubre [reúne núms. 403 y 404].

413. "Cuentos de Nana Lupe", Mundo, octubre y noviembre. 
414. Juan Ramón Jiménez, Poesías. Sel. y prỏl. de P. H. U. Ed. Cultura, México [v. núms. 352 y 390].

415. "Trabajo y lucha", prólogo a un libro de Carlos Gutiérrez Cruz.

416. J. M. Barrie, Peter Pan, el niño que nunca quiso crecer. Trad. y adap. de P. H. U., Mundo.

417. "Poeta y luchador" [Discurso de homenaje a Héctor Ripa Alberdi en la Escuela Preparatoria de México], Val, enero [quizá sea el mismo que se registra en el número siguiente].

418. "Héctor Ripa Alberdi" [Nota necrológica; fechada en México], CCon; Nos, abril de 1925; como prólogo en Obras de Ripa Alberdi, La Plata, 1925 [v. núms. 417 y $452]$.

419. "Emilio Pettoruti", Folleto de la Exposición Pettoruti, La Plata, 19 de octubre a 2 de noviembre; Val, enero de 1925.

420. "Romances tradicionales de México" [en colaboración con Bertram D. Wolfe], Homenaje a Menéndez Pidal, Madrid, t. 2, 1924, pp. 375-390.

421. "El hombre que era perro" [cuento], $C y C$.

422. "El supuesto andalucismo de América", Cuadernos del Instituto de Fílología, Buenos Aires, t. I, núm. 2, pp. 117-122 [v. núm. 533]. Con modificaciones de CurCon, 1936.

423. "La utopía de América" [+ "La patria de la justicia", en homenaje a Sánchez Viamonte el 7 de marzo], Ed. Estudiantina, La Plata. El segundo fue reproducido en RepAm, abril; ambos en $A n, 1933-1934$.

424. "La revolución y la cultura en México", RevFil, t. 1, pp. 125 y ss.

425. "Dos escritores de América. Icaza. García Godoy", Nos, abril o junio. 
426. "Caminos de nuestra historia literaria", Val, junio, agosto y septiembre [v. núm. 452].

427. "Eramos cuatro..." [cuento], CyC, agosto; Patria, 20 de febrero y 6 de marzo de 1926.

428. "Organicemos nuestra cultura. Las Bibliotecas", Val, septiembre [firmado L. R.].

429. "Nuestra crítica de arte", Val, septiembre [firmado L. R.].

430. "Situación parisiense y situación bonaerense", Val, septiembre [firmado L. R.].

431. "García Godoy", Patria, 21 de noviembre.

432. "La antigua sociedad patriarcal de las Antillas. Modalidades arcaicas de la vida en Santo Domingo durante el siglo XIX" [Conferencia en la Facultad de Ciencias Económicas de Buenos Aires], Patria, 20 y 25 de diciembre; RevEd, 1932.

\section{6}

433. Sobre Jorge Luis Borges, Inquisiciones. RFE, eneromarzo, t. 13, pp. 79-80; RepAm, 14 de abril de 1928.

434. "Un libro de Sanín Cano", Val; RepAm, 3 de julio.

435. "La civilización manual", Babel, Buenos Aires, agosto; Val.

436. "En busca del verso puro", Val, agosto de 1926, enero de 1927 y marzo de 1928; RepAm; CurCon, 1935 [con añadidos]; Homenaje a Enrique José Varona, La Habana, 1935 , pp. 29-48.

437. "La poesía argentina" [aclaraciones a la reseña de la Antología de Julio Noé], Val, agosto [con el título "Poesía argentina contemporánea" en núm. 452].

438. "El descontento y la promesa. En busca de nuestra expresión" [conferencia pronunciada en Amigos del Arte, Buenos Aires, el 28 de agosto], Nac, 29 de agosto; Rep$A m, 11$ de diciembre; Patria, noviembre de 1928; $A n$, abril de 1934 [v. núm. 452].

439. "Apuntes sobre poetas antillanos", Arch, julio; Lumen, Santo Domingo, octubre. 


\section{7}

440. El libro del idioma. Lectura, gramática, composición, vocabulario [para $5^{\circ}$ y $6^{\circ}$ grados de las escuelas primarias de la Prov. de Buenos Aires; en colaboración con Narciso Binayán], Kapeluzs, Buenos Aires ; $2^{2}$ ed., 1928; $3^{a}$ ed., 1929. [Tiene una Guía para el uso de...]. El prólogo se reprodujo en $\operatorname{RepAm}, 21$ de abril de 1928.

441. "Veinte años de literatura en los Estados Unidos", Nos; Patria, 26 de mayo; 2, 16, 23 y 30 de junio y 7 de julio de 1928 [v. núm. 452].

442. "Rafael Alberto Arrieta, Ariel corpóreo", Val, enero.

443. "Cultura argentina", Patria, 12 de febrero.

444. "Apuntaciones sobre la novela en América", Hum, t. 15, pp. 133-146; con el título "La novela en América", $R e$ novación, Ciudad Trujillo, 1945.

445. "Góngora, hijo del Renacimiento", $M F, 28$ de mayo; RepAm, 23 de julio; Patria, 10 de septiembre [con el título "Góngora" en núm. 593].

446. "Alfonso Reyes", Nac, 2 de julio; RepAm, 10 de diciembre [v. núm. 452].

447. "José María Gabriel y Galán", Hispania, California, t. 10, pp. 109-119 [¿ es el mismo de los núms. 129 y 182?].

448. Sobre Julio Rey Pastor, Los matemáticos españoles del siglo XVI. Val, [v. núm. 593].

\section{8}

449. "Siento que hemos despertado" [Carta a Joaquín García Monge a propósito de las publicaciones "Carta de Sandino", "Comité de Costa Rica", "Viaje de Pavlevich" y un artículo de García Monge], RepAm, 16 de junio.

450. "Notas sobre literatura inglesa", $H u m$, t. 18, pp. 103122 ; LyP, mayo de 1931, pp. 18-29. Contiene: núm. 209; "Al margen de la Historia de las ideas estéticas; "Bernard Shaw: a) El libro de P. P. Howe y b) núm. 275.

451. José Joaquín Pérez, La lira, Santo Domingo. Pról. de P. H. U. [v. núms. 79, 96 y 182].

452. Seis ensayos en busca de nuestra expresión, Babel, Buenos Aires, s. f. Contiene: “Orientaciones”, núms. 438, 
426, 371; "Figuras", 214, 247, 386 y 446; "Dos apuntes argentinos", 418, 347; "Panorama de la otra América", núm. 441; "Palabras finales".

1929

453. Cien de las mejores poesías castellanas, Buenos Aires; $2^{\text {a }}$ ed., Kapeluzs, 1941 [corregida y aumentada].

454. "Apuntes sobre poetas antillanos", Arch, julio; Luminar, México, octubre.

455. "Bibliografía literaria de Santo Domingo", RepAm, 7, 14 y 21 de septiembre [¿ es lo mismo que el núm. 370?]

456. Luis de Carrillo y Sotomayor, Fábula de Atis y Galatea. Sonetos. Ed. al cuidado de P. H. U. y Enrique Moreno. Pról. de P. H. U. Cuadernos de Don Segundo Sombra, La Plata [Pról. incluído en núm. 593].

1930

457. "El lenguaje", Hum, 21, pp. 107-125; BADL, 1946, núm. 21.

458. "Aspectos de la enseñanza literaria en la escuela común». Cuadernos de temas para la escuela primaria, 20, Fac. de Humanidades y Ciencias de la Educación, Univ. Nacional de La Plata; RevEd, diciembre de $1932 ; \operatorname{RepAm}$, a partir de mayo de 1933. Con el título "La enseñanza literaria en la escuela...", BIUP, 1933; Vang, 24 de noviembre de 1935; El Nacional, México, 12-16 de mayo de 1947.

459. "Música popular en América", Conferencias. Primer ciclo, Biblioteca del Colegio Nacional de la Univ. de La Plata, I, pp. 177-236.

460. "Danza y canción de América", Nac, 2 de marzo.

461. "Datos sobre el teatro en la América Latina", Monterrey, Río de Janeiro, núms. 1 y 2 , junio y agosto.

462. "Observaciones sobre el español en América", $R F E$, julio-septiembre, t. 17, pp. 277-284 [v. núms. 379 y 464].

\section{1}

463. "Letras y normas", Nac, 18 de enero. 
464. "Observaciones sobre el español en América”, $R F E$, abril-junio, t. 18, pp. 120-148 [v. núms. 379 y 462].

465. "Clásicos de América. I. Juan Ruiz de Alarcón", CurCon, julio; $L y P$, agosto de 1932, pp. 35-45.

466. "Clásicos de América. II. Sor Juana Inés de la Cruz", CurCon, septiembre; $L y P$, septiembre de $1932 ; A n, 1^{\circ}$ de diciembre de 1933.

467. "Martî", Sur, núm. 2, pp. 220-223; RepAm, 18 de julio. 468. "Dos vidas: Ibsen y Tolstoy", Nac. 20 de diciembre.

\section{2}

469. "Héroes de sacrificio". [En homenaje a Duarte, Sánchez y Mella; 20 de marzo de 1932], RevEd, marzo, núm. 13.

470. “Alarcón y el espíritu mexicano", $L y P$, abril.

471. "Lo agradece, pero lo lamenta" [Carta a Horacio Blanco Fombona (Santo Domingo, 23 de junio) sobre errores y omisiones en que, por confusión, se le hace incurrir en una entrevista con el periodista G. A. Romeu, publicada en Puerto Rico y reproducida en $B a$, dirigida por Blanco Fombona], $B a, 2$ de julio.

472. "La tercera dimensión de la República española" [Confencia improvisada en la velada necrológica celebrada el 14 de diciembre en recuerdo de Galán y García Hernández], RepAm, 15 de diciembre de 1933.

473. "Palabras en la investidura de bachilleres de la Escuela Normal de Santo Domingo", RevEd, diciembre.

474. "El modelo estrófico de las layes, deçires y canciones de Rubén Darío", $R F E$, octubre-diciembre, t. 19, pp. 421$422 ; \operatorname{RepAm}, 1934$.

475. "La inconveniencia de los exámenes espectaculares", RepAm.

476. "Heredia y los pinos del Niágara", RepAm.

477. "Woss y Gil y los pinos del Niágara", Ba; Social.

478. Emiliano Tejera, Palabras indígenas de la Isla de Santo Domingo. Pról. de P. H. U. (Santo Domingo). 
479. Nicolás Ureña de Mendoza, Poesías. Colec. por P. H. U., Santo Domingo (30 pp. mimeografiadas).

480. "Palabras del superintendente de enseñanza P. H. U. en la inauguración del mausoleo de Luisa Ozema Pellerano de Henríquez" (28 de marzo), La escuela normal y el instituto de señoritas, Páginas para la historia de la Cultura Dominicana, Impr. La Nacional, Santo Domingo.

481. "Niebla" [Texto impresionista escrito al llegar a Francia en julio], Número, México; De Mar a Mar, 6 ?, año 2, núm. 4, mayo de 1943.

482. "Historia del Arte en América" [Cartas de P. H. U. y R. Menéndez Pidal], Clío, julio-agosto.

483. "Raza y cultura" [Palabras pronunciadas en nombre de la Univ. Nacional de La Plata el 11 de octubre con motivo del Día de la Raza], RepAm, 6 de enero de 1934; con el título "Raza y cultura hispánicas" en $A n, 24$ de febrero de 1934; Vang, 13 de octubre de 1935.

\section{4}

484. "Comienzos del español en América", $\mathrm{Nac}, 18$ de febrero; CurCon, núm. 12.

485. "La poesía popular" [dominicana], $B a, 14$ y 21 de abril.

486. "Bernard Shaw y la economía política", Nac, 12 de mayo [v. núm. 504].

487. "Observaciones sobre el español en México", InvLing, julio-octubre, t. 2, pp. 188-194.

488. Sobre Samuel Montefiore Waxman, A bibliography of the belles lettres of Santo Domingo [en colaboración con Gilberto Sánchez Lustrino), $R F E$, t. 21, julio-septiembre, pp. 293-309.

489. "Casa de apóstoles", Nac, 18 de noviembre; RepAm, 16 de marzo de 1935.

490. "La colección latinoamericana" [de la Biblioteca de la Universidad de La Plata], BUNLP, núm. 4.

491. "En mi tierra...", RepAm.

492. "Literatura contemporánea de la América Española", $B U N L P$, t. 18 , núm. 5.

493. Mario Irle, Plenitud en goce y lágrima. Pról. de P.H.U. Santo Domingo. 


\section{5}

494. "Enriquillo", Nac. 13 de enero.

495. "Escritores españoles en la Universidad de México", $R F E$, enero-marzo, t. 22 , pp. 60-65; Clio, julio-agosto, pp. 103-105.

496. "Palabras antillanas en el diccionario de la Academia", $\dot{R} F E$, t. 22, abril-junio, pp. 175-184; $B A D L$, abril de 1942, núm. 7.

497. "Ciudadano de América" [Eugenio María de Hostos], Nac, 28 de abril; prólogo a la Moral Social, Buenos Aires, 1939 y a la ed. francesa de Essais, París, 1936.

498. "Poesía contemporánea" [Sobre la Antología de Federico de Onís], Nac, 31 de mayo; RepAm, $1^{\circ}$ de junio.

499. "Poesía tradicional" [Comentarios a Dámaso Alonso, Poesía de la Edad Media y poesía tradicional], Nac, 4 de agosto [v. núm. 593].

500. "Esplendor, eclipse y resurgimiento de Lope de Vega", Nac, 25 de agosto; $L D, 12$ de octubre [v. núm. 593].

501. "España y el Renacimiento", Nac, 10 de noviembre; $B a$, 18 y 25 de enero de 1936; CurCon, diciembre de 1938, pp. 861-867 [retocado y con el título "Cultura española]. Bajo el título "España en la cultura moderna", en núm. 593.

502. "Erasmistas en el Nuevo Mundo", Nac, 8 de diciembre; $B a, 22$ de febrero de 1936; $C D C, 2,1943$.

503. "Lope de Vega. Tradición e innovación", Sur. [Con el título "Tradición e innovación" en núm. 593].

504. "Bernard Shaw. I, Vida y Obra;; II, Shaw y la economía política» [v. núm. 486]; III, Filosofía y estética", CurCon, pp. 594-608, 786-795, 1155-1164. Hay resúmenes de E. Anderson Imbert en $\operatorname{Rep} A m$, mayo de 1936.

505. "Brasil literario", $B U N L P$, t. 19, núm. 2.

\section{6}

506. "Camino interior" [sobre la novela americana], Sur, enero, pp. 76-77; RepAm.

507. “Don Ramón del Valle-Inclán", Nac, 26 de enero; RepAm. 
508. "El maestro de Cuba: Enrique José Varona", Nac, 15 de marzo; RevC, Ba y RepAm; UnivMéx, 2, núm. 11, pp. 39-41.

509. "Paisajes y retratos" [Colón y Las Casas], Nac, 31 de mayo.

510. "El peso falso" [cuento], Nac, 12 de julio.

511. "Chesterton", Nac, 26 de julio; UnivMéx, febrero de 1937; RepAm, 1937.

512. "Dos valores hispanoamericanos. Sanín Cano y Enrique Díez-Canedo", Sur, agosto, pp. 133-136.

513. "La sombra" [cuento], Nac, 30 de agosto.

514. "La América Española y su originalidad", Nac, 27 de septiembre; Vang, 11 de abril de 1937.

515. "Filosofía y originalidad" [Sobre Aníbal Sánchez Reulet], Sur, septiembre, pp. 124-127.

516. "El teatro de la América Española en la época colonial" [Conferencia pronunciada el 21 de septiembre en el Teatro Nacional de Comedia], Cuadernos de Cultura Teatral, Instituto Nacional de Estudios de Teatro, núm. 3, pp. 9-50 (Buenos Aires).

517. "Teatro colonial", Nac, 22 de septiembre.

518. "Sobre literatura colonial en América", $R F E$, octubrediciembre, t. 23, pp. 410-413.

519. "Palabras pronunciadas en el Primer Congreso Gremial de Escritores", Sur, noviembre, pp. 140-141.

520. "Korn", Vang, 8 de noviembre; con el título "Dr. Alejandro Korn" en RepAm.

521. "Teatro hispano indígena", Nac, 22 de noviembre.

522. "Cunningham Graham", Nos.

523. "Lo que aportó el descubrimiento del Nuevo Mundo a la visión y la literatura del Viejo Continente", $L D$.

524. "Sepamos quién era. Enrique Díez-Canedo", Sur.

525. "Problemas del verso español. La versificación fluctuante en la poesía de la Edad Media", CurCon, pp. 491505.

526. "Un maestro", RepAm.

527. La cultura y las letras coloniales en Santo Domingo, $R D H$, anejo 2 [pasajes en Nac, 20 de diciembre]. 


\section{7}

528. "El idioma español y la historia política en Santo Domingo", Segundo Congreso Internacional de Historia de América reunido en Buenos Aires del 5 al 14 de julio de 1937. Buenos Aires, 1938.

529. "El español en la zona del Mar Caribe", Nac, $1^{\circ}$ de agosto.

530. "Esquema de la Historia de la Literatura, en especial de la Literatura Argentina", Vang, 8 de agosto.

531. "El español en México y sus vecindades", Nac, 5 de septiembre.

532. "In memoriam. Genaro Estrada", Sur, octubre, pp. 8586 ; con el título "Genaro Estrada" en $R e p A m, 12$ de febrero de 1938.

533. Sobre el problema del andalucismo dialectal en América, $B D H$, anejo I [v. núm. 422].

534. Antología clásica de la literatura argentina [en colaboración con Jorge Luis Borges], Kapeluzs, Buenos Aires.

535. La Liga de las Naciones Americanas y la Conferencia de Buenos Aires [discurso ante la Asamblea], New York, L. y S. Printing Co.

536. "Cultura española de la Edad Media desde Alfonso el Sabio hasta los Reyes Católicos", Historia de la Nación Argentina [dirigida por Ricardo Levene], t. 2, Buenos Aires, pp. 175-209 [Con el título "Cultura española de la Edad Media" en núm. 593].

537. "Problemas del español en México" [Sobre Jesús González Moreno, Etimologías del español], InvLing, 4, núms. 1-2, pp. 56-57.

538.. "Las universidades", $A U S D$, pp. 70-77 [cap. del núm. $527]$.

539. "En mi tierra...", RepAm.

540. "Vida espiritual en Hispanoamérica", Europa-América latina, Buenos Aires.

541. La vida del Lazarillo de Tormes. Estudio preliminar y edición de P.H.U. Colec. Universal, Buenos Aires.

1938

542. "Caribe", Nac, 19 de junio. 
543. "Historia de palabras" [batata], Nac, 24 de julio.

544. "La planta enigmática" [el aje], $N a c, 4$ de septiembre.

545. "Carta a García Monge" [le remite el Manifiesto de los intelectuales dominicanos al pueblo y al gobierno de España; fechada en Buenos Aires el 12 de diciembre], RepAm, 1939.

546. "El enigma del aje", $R A A$, 5, núm. 4, pp. 209-221 [incluido en núm. 549].

547. "Estudios sobre el español en Nuevo México", $M L R$.

548. "Bibliografía literaria de la América Española", BICLA, pp. 67-70, 74-78, 97-103; 1943, pp. 416-621.

549. Para la historia de los indigenismos. Papa y batata. El enigma del aje. Boniato. Caribe. Palabras antillanas, $B D H$, anejo 3.

550. El español en México, los Estados Unidos y la América Central [Incluye trabajos de Hills, Semeleder, Carrol Marden, Revilla, Nykl, Lentzner, Gagini y Cuervo], con anotaciones y estudios de P.H.U., $B D H, 4$. [pasajes reproducidos en RevC].

551. Gramática castellana [en colaboración con Amado Alonso], Primer Curso, Losada, Buenos Aires; $2^{a}$ ed. [corregida], $1941 ; 3^{\mathrm{a}}$ ed., $1943 ; 4^{\mathrm{a}}$ ed., $1943 ; 5^{\mathrm{a}}$ ed., 1945 ; $6^{n}$ ed., $1946 ; 7^{\text {a }}$ ed., 1947; $8^{\text {a }}$ ed., 1949; $9^{2}$ ed., 1950; $10^{\mathrm{a}}$ ed., $1951 ; 11^{\mathrm{z}}$ ed., $1953 ; 12^{\mathrm{a}}$ ed., 1955 [v. núm. 566].

552. Juan Ruiz de Alarcón, La verdad sospechosa. Ed. al cuidado de P.H.U. y Jorge Bogliano; introd. de P.H.U., Buenos Aires.

553. Sor Juana Inés de la Cruz, Obras escogidas. Ed. y pról. de P. H. U. y Patricio Canto. Colec. Austral, Buenos Aires, núm. 12; hay ya varias ediciones.

\section{Las Cien Obras Maestras}

554. Poema del Cid. Texto antiguo de la ed. de R. Menéndez Pidal y versión en romance moderno de Pedro Salinas. Introducción de P.H.U., Losada, Buenos Aires, vol. 1, $2^{a}$ ed., 1940; $3^{a}$ ed., 1943; $4^{a}$ ed., 1946; $5^{a}$ ed., 1951.

555. Domingo Faustino Sarmiento, Facundo. Introd. de P. 
H. U., Losada, Buenos Aires, vol. 2 ; $2^{2}$ ed., 1942; $3^{a}$ ed., $1945 ; 4^{a}$ ed., 1947.

556. Fernando de Rojas, La Celestina. Introd. de P.H.U., Losada, Buenos Aires, vol. 4. [Introd. en núm. 593]; $2^{a}$ ed., 1941; $3^{\text {a }}$ ed., 1947.

557. Homero, La Odisea. Trad. de Segalá y Estalella. Introd. de P. H. U., Losada, Buenos Aires, vol. 5 ; $2^{\text {a }}$ ed., 1941; $3^{3}$ ed., 1947.

558. Lope de Vega, Fuenteovejuna, Peribáñez y el comendador de Ocaña, El mejor alcalde el Rey. Introd. de P.H.U., Losada, Buenos Aires, vol. 6 [Con el título de "Las tragedias populares de Lope" se reprodujo la introducción en Conducta al servicio del pueblo, Buenos Aires, 6 de abril de 1939 y en núm. 593] ; $2^{a}$ ed., $1942 ; 3^{a}$ ed., 1945.

559. "Biografía mínima: Eugenio María de Hostos, 18391939", BICLA, enero-febrero.

560. "Ello", $R F H$, t. 1, núm. 3, julio-septiembre, pp. 209-229; $B A D L$, julio-noviembre de 1942.

561. Sobre Ramón Menéndez Pidal, Poesía árabe y poesía europea. $R F H$, t. 1, núm. 3, julio-septiembre, pp. 285289.

562. "Centenarios" [Hostos], Sur, agosto, pp. 52-54.

563. "De la vida de Shakespeare", Nac, 10 de septiembre.

564. "Documentos" [contestación a Ozorio Almeyda], Sur, octubre, pp. 118.

565. Sobre Alfonso Par, Shakespeare en la literatura española. RFH, t. 1, núm. 4, octubre-diciembre, pp. 393-394.

566. Gramática castellana [en colaboración con Amado Alonso] Segundo Curso, Losada, Buenos Aires; $2^{a}$ ed. [corregida], 1941; $3^{3}$ ed., 1943; $4^{\text {a }}$ ed., 1943; $5^{\text {a }}$ ed., 1945; $6^{\mathrm{a}}$ ed., $1946 ; 7^{\mathrm{a}}$ ed., $1947 ; 8^{\mathrm{a}}$ ed., $1949 ; 9^{\mathrm{a}}$ ed., 1950 ; $10^{\mathrm{a}}$ ed., $1951 ; 11^{\mathrm{a}}$ ed., $1953 ; 12^{\mathrm{a}}$ ed., 1955 [v. núm. 551].

567. José Martí, Nuestra América. Introd. de P.H.U. Colec. Grandes Escritores de América, Buenos Aires.

568. Eugenio María de Hostos, Moral Social. Introd. de P. H. U. Colec. Grandes Escritores de América, Buenos Aires. 
Las Cien Obras Maestras

569. Miguel de Cervantes, Novelas ejemplares. Introd. de P. H. U., Losada, Buenos Aires, vol. 7. [Introd. en núm. 593]; $2^{\text {a }}$ ed., $1942 ; 3^{\text {a }}$ ed., 1947.

570. Infante Juan Manuel, Libro de los ejemplos del Conde Lucanor y de Patronio. Introd. de P.H.U., Losada, Buenos Aires, vol. $9 ; 2^{\text {a }}$ ed., 1942; $3^{\text {a }}$ ed., 1947.

571. Esquilo, Tragedias. Pról. de P.H.U., Losada, Buenos Aires, vol. $10 ; 2^{\mathrm{a}}$ ed., $1941 ; 3^{\mathrm{a}}$ ed., 1947.

572. Homero, La Ilíada. Introd. de P.H.U., Losada, Buenos Aires, vol. 11; $2^{\text {a }}$ ed., 1943; 3* ed., 1945; $4^{a}$ ed., 1953.

573. Pedro Calderón de la Barca, La vida es sueño, El alcalde de Zalamea, El mágico prodigioso. Introd. de P.H.U., Losada, Buenos Aires, vol. 13. [Introd. en núm. 593]; $2^{a}$ ed., $1943 ; 3^{\mathrm{a}}$ ed., 1947.

574. Tirso de Molina, El burlador de Sevilla, El condenado por desconfiado, La prudencia en la mujer. Introd. de P.H.U., Losada, Buenos Aires, vol. 14. [Introd. en núm. 593]; $2^{\mathrm{a}}$ ed., 1943.

575. Luis de Góngora, Romances y letrillas. Introd. de P.H.U., Losada, Buenos Aires, vol. 15 [Introd. en núm. 593 y v. núm. 445] ; $2^{3}$ ed., 1944.

576. Luis de Góngora, Poemas y sonetos. Introd. de P.H.U., Losada, Buenos Aires, vol. 16 [Introd. en núm. 593 y v. núm. 445]; $2^{\mathfrak{a}}$ ed., 1943.

577. Plutarco, Vidas paralelas. Introd. de P.H.U., Losada, Buenos Aires, vol. 17.

578. Shakespeare, Otelo, Romeo y Julieta. Introd. de P.H.U., Losada, Buenos Aires, vol. 18; $2^{\text {z }}$ ed., 1944.

579. Jean Racine, Fedra, Andrómaca, Británico, Ester. Introd. de P. H. U., Losada, Buenos Aires, vol. 21.

\section{0}

580. Sobre Halfdan Gregersen, Ibsen and Spain. A study in comparative drama. RFH, t. 2, núm. 1, enero-marzo, pp. 58-64.

581. "Cosas de las Indias", Nac, 4 de febrero; Ozama, Ciudad Trujillo, julio-agosto de 1941. 
582. Sobre Sister Mary Paulina Saint Amour, A study of the villancico up to Lope de Vega: its evolution from profane to sacred themes, and specifically to the Christmas carol. RFH, t. 2, núm. 2, abril-junio.

583. "Tierra lejana", Nac, 7 de abril.

584. "Barroco de América", Nac, 23 de junio; NacT, 6 de julio de 1941.

585. "Debates sobre temas sociológicos: En torno a «Defensa de la República», Sur, agosto, pp. 86-104.

586. "Debates sobre relaciones interamericanas", Sur, septiembre, pp. 100-123.

587. "La América Española y su originalidad", Nac, 27 de septiembre.

588. Sobre Jefferson Rea Spell, Mexican literary periodicals of the twentieth century, RFH, t. 2, núm. 4, octubrediciembre, pp. 407-408.

589. "El problema histórico de la organización de nuestro pueblo", Vida y Obra, Revista del Centro de Estudios Venezolanos, La Plata, noviembre.

590. "La emancipación y primer período de la vida independiente en Santo Domingo", Historia de América [dirigida por Ricardo Levene], t. 7, pp. 381-425.

591. "Historia contemporánea de la isla de Santo Domingo. La República Dominicana desde 1873 hasta nuestros días, y Puerto Rico en el siglo xx", Historia de América [dirigida por Ricardo Levene], t. 9, pp. 463-488 y 489501.

592. El español en Santo Domingo, BDH, 5.

593. Plenitud de España, Losada, Buenos Aires, Biblioteca Contemporánea. Contiene: núms. 501, 245, 503, 500, 244, 536; "Apuntaciones marginales", núms. 499, 556, 448, 569, 558, 574, 573, 575, 576, 456 ; "Explicación"; $2^{n}$ ed., 1945 [corregida y aumentada; v. núm. 623].

\section{Las Cien Obras Maestras}

594. Francisco de Quevedo y Villegas, El Buscón y Escritos breves. Introd. de P.H.U. Losada, Buenos Aires, vol. 28. 
595. Santa Teresa de Jesús, Las Moradas o Castillo interior y conceptos del amor divino. Introd. de P.H.U., Losada, Buenos Aires, vol. 29.

596. Molière, Tartufo, La escuela de los maridos, El burgués gentilhombre. Introd. de P.H.U., Losada, Buenos Aires, vol. 30.

597. Shakespeare, Hamlet. Introd. de P.H.U., Losada, Buenos Aires, vol. 34.

\section{1}

598. Sobre Concerning Latin American culture, edited by Charles C. Griffin. RFH, t. 3, núm. 3, julio-septiembre, pp. 279-281.

599. "Debates sobre temas sociológicos. Acerca de Los irresponsables de Archibald Mac Leish", Sur, agosto, pp. 99-126.

600. Sobre José Ferrater Mora, Diccionario de Filosofía [en colaboración con Raimundo Lida], RFH, t. 3, núm. 4, octubre-diciembre, pp. 396-398.

601. "Nacionalismo", La Información, Santo Domingo, octubre.

602. "Debates sobre temas sociológicos. ¿Tienen las Américas una historia común?", Sur, noviembre, pp. 83-103.

603. "Literatura de Santo Domingo y Puerto Rico", Historia universal de la literatura de Santiago Prampolini, t. 12, Buenos Aires, pp. 77-95.

604. "Literatura de la América Central", Historia universal de la literatura de Santiago Prampolini, t. 12, Buenos Aires, pp. 105-121.

605. "Palabras americanas en la despedida de un buen americano", Public. de la Universidad Popular Alejandro Korn, La Plata. Versión de las palabras que pronunció P.H.U. sobre la cultura hispanoamericana.

606. George Santayana, La aversión al platonismo. Trad. de P. H. U. Incluído en la selección Diálogos en el limbo, Buenos Aires.

607. "Emiliano Tejera. Página de honores póstumos", Clío. 
Las Cien Obras Maestras

608. Aristófanes, Las nubes, Los arcanienses, Los caballeros. Introd. de P.H.U., Losada, Buenos Aires, vol. 36.

1942

609. Sobre Revista de Literatura Mexicana. $R F H$, t. 4, núm. 1, enero-marzo, pp. 98-100.

610. Sobre Victoria Ocampo, Testimonios (Segunda serie), Sur, febrero, pp. 65-67.

611. "La versificación de Heredia", $R F H$, t. 4, núm. 2, abril-" junio, pp. 171-172.

612. Sobre Lloyd J. Read, The Mexican historical novel, 18261910. RFH, t. 4, núm. 2, pp. 188-189.

613. Sobre Flérida de Nolasco, La música en Santo Domingo $y$ otros ensayos. RFH, t. 4, p. 190.

614. "Desagravio a Borges", Sur, julio, p. 13.

615. Sobre Georgiana Goddard King, Heart of Spain. RFH, t. 4, núm. 3, julio-septiembre, pp. 292-294.**

617. "Debates sobre temas sociológicos. El problema Gandhi", Sur, noviembre, pp. 81-97.

618. "Influencia del descubrimiento en la literatura" [Coloquios sobre el descubrimiento patrocinados por la Institución Cultural Española], Sur, noviembre, pp. 11-15.

619. Archibald Mac Leish, Los irresponsables. Trad. de P. H. U., Pedro Lecuona y Francisco Aguilera, Losada, Buenos Aires.

\section{3}

620. Sobre Jorge Manrique, Cancionero (Est., ed. y pról. de Augusto Cortina), $R F H$, t. 5, núm. 1, enero-febrero, pp. 72-73.

621. Sobre J. Warshaw, Jorge Isaacs' Library. Light on two "María" problems. $R F H$, t. 5, núm. 1, enero-marzo, pp. 99-100.

* El núm. 616 se suprimió porque había sido incluido equivocadamente. 
622. Sobre Louis H. Gray, Six romance etymologies. RFH, t. 5, núm. 1, enero-marzo, pp. 100-101.

623. "Guillermo Valencia", $B A A L$, julio-septiembre, t. 9, núm. 43, pp. 617-618.

624. "El Arcipreste de Hita" [Conferencia pronunciada en la Facultad de Filosofía y Letras de Buenos Aires el 17 de septiembre], Sur, noviembre, pp. 7-25 [incluída en la $2^{n}$ ed. de núm. 593].

\section{4}

625. Sobre Alexander Parker, The allegorical drama of Calderón. An introduction to the autos sacramentales. $R F H$, t. 6, núm. 2, abril-junio, pp. 197-199.

626. "Cincuenta años", Nac, 4 de junio; trad. al portugués por Acácio França en $A$ Manhã. Río de Janeiro, 5 de mayo de 1945.

627. "Los jueces de Castilla", $R F H$, t. 6, núm. 3, julio-septiembre, pp. 285-286.

628. "Horacio en México", $R F H$, t. 6, núm. 3, julio-septiembre, p. 286.

629. "Papa y batata. Notas adicionales (I. de Llorens Castillo; II, de P. H. U.)", $R F H$, t. 6, núm. 4, octubre-diciembre, pp. 387-394 [v. núm. 549].

630. Sobre Emilio Rodríguez Demorizi, Vicisitudes de la lengua española en Santo Domingo. RFH, t. 6, núm. 4, octubre-diciembre, pp. 409-410.

631. "Rufino José Cuervo", $B A A L$, octubre-diciembre, t. 13, núm. 49, pp. 697-698.

632. "The English Poets in Pictures. Letters of John Keats", Sur, diciembre, pp. 59-60.

633. "La literatura en los periódicos argentinos" [Trabajo de investigación dirigido por P.H.U., con la intervención de Dora Gumpel y Mario Muñoz Guilmar], Revista de la Universidad de Buenos Aires, tercera época, año 2, núm. 4 , pp. 245-258; 1945, año 3, núm. 1, pp. 41-53, núm. 2, pp. 237-267 y núm. 4, pp. 259-283; 1946, año 4, núm. 1, pp. 85-124. 
634. “El endecasílabo castellano", $B A A L$, t. 13, pp. 725-824 [v. núms. 161, 182 y 355].

635. "Esta carta..." [fechada en Buenos Aires el 27 de diciembre], Rep $A m, 26$ de febrero de 1945.

\section{5}

636. "La cuaderna vía", $R F H$, t. 7, núm. 1, enero-marzo, pp. 45-47.

637. Sobre Remigio Hugo Pane, English translations from the Spanish, 1484-1943. A bibliography. RFH, t. 7, núm. 1, enero-marzo, pp. 71-74.

638. "Pasado y presente", Nac, 25 de febrero; $C D C$, núm. 22 ; Letras de México, $1^{\circ}$ de abril de 1945.

639. Sobre Lawrence B. Kiddle, The Spanish word "jicara". A word history. With an appendix... RFH, t. 7, núm. 3, julio-septiembre, pp. 288-290.

640. "Perfil de Sarmiento", $C u A$, año 4, núm. 5, septiembreoctubre, pp. 199-206 [Traducción de un fragmento del cap. 5, de núm. 642].

641. "Reseña de la historia cultural y literaria de la República Dominicana", Colec. Panamericana, núm. 28, Ed. Jackson, Buenos Aires.

642. Literary Currents in Hispanic America, Harvard University Press, Cambridge, Massachusetts.

\section{6}

643. "Sobre la historia del alejandrino", $R F H$, t. 8, núms. 12, enero-junio, pp. 1-11.

644. "Que sobreviva y se reanime..." [Cortesía con motivo del núm. 1000 de $R \operatorname{epA} A$ ], RepAm, 20 de enero.

Publicaciones póstumas, recopilaciones ajenas y homenajes***

645. Homenaje a Pedro Henriquez Ureña, Letras, Boletín del Círculo de Profesores de Castellano y Literatura, Buenos

*** En los homenajes sólo se indican los trabajos de P.H.U. 
Aires, t. 1, núm. 4, diciembre de 1946. Contiene: "El descubrimiento del nuevo mundo en la imaginación europea" [trad. del cap. 1 del núm. 642 por Fanny Rubín], núms. 481, 510, 507 y 458.

646. Páginas escogidas. Pról. de Alfonso Reyes. Selec. de José Luis Martínez, Biblioteca Enciclopédica Popular, vol. 109, Secretaría de Educación Pública, México, 1946. Contiene: núms. 140, 148, 137, 214, 245, "La antología de la ciudad" [v. núm. 390], 209, 467, 501, 527 [pp. 913], 556 [prólogo], 618.

647. Historia de la Cultura en la América Hispánica, Colec. Tierra Firme, núm. 28, Fondo de Cultura Económica, México, 1947; $2^{\text {a }}$ ed., 1949; 3ㄹ ed., 1955.

648. Las corrientes literarias en la América Hispiánica. Trad. del núm. 641 por Joaquín Díez-Canedo. Biblioteca Americana, núm. 9, Fondo de Cultura Económica, México, $1949 ; 2^{\text {a }}$ ed., 1954.

649. Poesías juveniles. Colec. y ed. de E. Rodríguez Demorizi, Ediciones Espiral Colombia, Bogotá, 1949. Contiene núms. $14,17,18,27,33,38,43,37,47,53,46,40,61$; $58,85,80,81,135,170,171,294,143$.

650. Antología. Selec., pról. y notas de Max Henríquez Ureña, Librería Dominicana, Ciudad Trujillo, 1950. Contiene núms. 146, 167, 214, 157, 245, 209, 423, 438, 426, 436, 513, 527 [pasajes], "El papel de Santo Domingo en la historia lingüística de América" [pasajes de núm. 592], 640, "Los intelectuales en la independencia americana" [pasajes de núm. 647].

651. Plenitud de América. Ensayos escogidos. Selec. y nota preliminar de Javier Fernández, Peña, del Giúdice-editores, Buenos Aires, 1952. Contiene núms. 423, 438, $483,514,540,638,424,626,584,502,605,69,640$, 497, 508, 467, 469, 494, 512.

652. Ensayos en busca de nuestra expresión, Ed. Raigal, Buenos Aires, 1952. Con una "Evocación de Pedro Henríquez Ureña" de Alfonso Reyes y un "Homenaje a Pedro Henríquez Ureña" de Ezequiel Martínez Estrada. Con- 
tiene núms. 423, 514, 438, 426, 444, 371, 527 [pp. 9-13], $214,640,497,467,188,247,446,418$.

653. El Instituto de Filología de la Facultad de Filosofía y Letras de Buenos Aires prepara una edición de todos los trabajos de P.H.U. sobre cuestiones métricas.

\section{Emma Susana Speratti PiÑero, El Colegio de México.}

\section{SIGLAS CORRESPONDIENTES A LA BIBLIOGRAFIA}

Act.-Actualidades, México.

An.-Analectas, Santo Domingo.

An-re.-Anti-reeleccionista, México.

Arch.-Archipiélago, Santiago de Cuba.

Ateneo.-Ateneo, Santo Domingo.

$A U S D$.-Anales de la Universidad de Santo Domingo, Ciudad Trujillo.

Ba.-Bahoruco, Santo Domingo.

$B A A L$.-Boletín de la Academia Argentina de Letras, Buenos Aires.

$B A D L$. - Boletín de la Academia Dominicana de la Lengua, Santo Domingo.

BBMP. - Boletín de la Biblioteca Menéndez y Pelayo, Santander.

$B D H$.-Biblioteca de Dialectología Hispanoamericana, Buenos Aires.

BICLA.-Boletín del Instituto de Cultura Latino-Americana, Buenos Aires.

BIUP.-Boletín de la Unión Panamericana, Washington. BUNLP.-Boletín de la Universidad Nacional de La Plata, La Plata.

CCon.-Cuba Contemporánea, La Habana. mingo.

CDC.-Cuadernos Dominicanos de Cultura, Santo Do-

Clío.-Clío, Santo Domingo.

CLit.-Cuba Literaria, Santiago de Cuba.

CMus.-Cuba Musical, La Habana.

Crónica.-Crónica, Guadalajara (México).

CuA.-Cuadernos Americanos, México.

Cuna.-La Cuna de América, Santo Domingo.

CurCon.-Cursos y Conferencias, Buenos Aires.

CyAm.-Cuba y América, La Habana. 
CyC.-Caras y Caretas, Buenos Aires.

Dictamen.-El Dictamen, Veracruz.

Discusión.-La Discusión, La Habana.

España.-España, Madrid.

Est.-El Estudiante, México.

Fig.-_El Fígaro", La Habana.

HeCu.-El Heraldo de Cuba, La Habana.

HeR.—El Heraldo de la Raza, México.

Hisp.-Hispania, Madrid.

Hum.-Humanidades, La Plata.

Ib Am.-El Ibero-Americano, Santo Domingo.

Ideal.-El Ideal, Santo Domingo.

Imparcial._El Imparcial, México.

InvLing.-Investigaciones Lingüísticas, México.

$L D$.-Listín Diario, Santo Domingo.

LHab.-Letras, La Habana.

Lucha.-La Lucha, Santo Domingo.

LyC.-Letras y Ciencias, Santo Domingo.

LyP.-El Libro y el Pueblo, México.

$M F$--Martín Fierro, Buenos Aires.

MIl.-El Mundo Ilustrado, México.

MinD.-The Minnesota Daily, Minneapolis.

$M I R$.-Modern Language Review, Liverpool.

MM.-México Moderno, México.

Mundo.-El Mundo, México.

Nac.-La Nación, Buenos Aires.

NacT.LLa Nación, Ciudad Trujillo.

Nos.-Nosotros, Buenos Aires.

NosM.-Nosotros, México.

Nov. - Las Novedades, New York.

NP.-Nuevas Páginas, Santo Domingo.

Oiga.-Oiga. .., Santo Domingo.

Osiris.-Osiris, Santo Domingo.

Pan.-Panfilia, Santo Domingo.

Patria.-Patria, Santo Domingo.

Pr.-La Prensa, New York.

PrIl.-La Propaganda Ilustrada, New York.

Quijote.-Don Quijote, Puebla (México).

Quincena.-La Quincena, San Salvador.

$R A A$.-Revista Argentina de Agronomía, Buenos Aires.

$R A z$. -Revista Azul, México.

RepAm.-Repertorio Americano, San José de Costa Rica.

RevBC.-Revista Bimestre Cubana, La Habana.

RevC.-Revista Cubana, La Habana.

RevCrit.-Revista Crítica, Veracruz.

RevEd.-Revista de Educación, Santo Domingo.

RevFil.-Revista de Filosofía, Buenos Aires. 
RevInd.-Revista de Indias, New York.

RevLit.-Revista Literaria, Santo Domingo.

RevMod.-Revista Moderna de México, México.

RevRev.-Revista de Revistas, México.

RFE.-Revista de Filología Española, Madrid.

$R F H$.-Revista de Filología Hispánica, Buenos Aires.

RHi.-Revue Hispanique, París.

$R R$. The Romanic Review, New York.

RUniv.-Revista Universal, México.

SavM.-Savia Moderna, México.

Social.-Social, La Habana.

Sur.-Sur, Buenos Aires.

Tel.-El Teléfono, Santo Domingo.

Tilin.-Tilín-Tilín, México.

Trap.-Trapalanda, Buenos Aires.

TyM.-Teatros y Música, México.

UnHisp.-La Unión Hispanoamericana, Madrid.

UnivMéx.-Universidad de México, México.

Val.-Valoraciones, La Plata.

Vang.-La Vanguardia, Buenos Aires.

VidM._Vida Moderna, México.

\section{NOTAS}

1. En el manuscrito de P.H.U. están abarcadas por una llave y tienen la inscripción "juguetes infantiles". No las recoge.

2. Figuran en el ms. con el subtítulo "Balbuceos".

3. En el ms. con el subtítulo "Del cercado ajeno".

4. En el ms. con el subtítulo "Leyenda indígena".

5. Sin firma.

6. Con la firma "Bohechio".

7. En el ms. con el subtítulo "Pesimismos".

8. En el ms. con el subtítulo "Modernismos otoñales".

9. En el ms. con el subtítulo "Galantes".

10. Con la firma "León Roch".

11. La siguiente nota manuscrita acompaña al ejemplar del archivo de P.H.U.: "En este cuento solamente la firma y la idea son de P.H.U.; la factura y el estilo son de Arturo R. Carricarte".

12. Con la firma P.H.U.

13. Con la firma "M. de Phocás".

14. Con la firma "E. P. Garduño".

15. Con la firma "Gogol". 
Estudios ofrecidos a la memoria del Dr. PEDRO HENRIQUEZ UREÑA 
